\title{
The Role of Legally Available "Ergogenic" Nutritional Supplements in Exercise Performance: A Biochemical and Physiological Approach
}

\author{
Ioannis Delimaris* \\ Ministry of Education, Research and Religious Affairs, Greece
}

Submission: March 07, 2017; Published: March 22, 2017

*Corresponding author: Ioannis Delimaris, Ministry of Education, Research and Religious Affairs, Athens, Greece,

Email: dr.i.delimaris@gmail.com

\section{Abstract}

Introduction: Numerous supplements are marketed today as "ergogenic". However, the available literature is still lacking conclusive information, while there is a large heterogeneity in the reported scientific data.

Objective: The aim of the present study is to investigate the role of legally available (according to the World Anti-Doping Code) "ergogenic" nutritional supplements in exercise performance using a biochemical and physiological approach.

Material: The literature available in the online databases Medline, PubChem, Toxnet, and Google Scholar was used.

Method: The research methodology refers to the brief review of the available published scientific studies. The literature search was conducted using the following terms / keywords: "ergogenic supplements", "ergogenic aids" and "exercise performance".

Results and discussion: The most popular and commonly used legally available "ergogenic" supplements by athletes are sodium bicarbonate, beta-alanine, beta-hydroxy-beta-methylbutyric acid (HMB), creatine, carnitine, caffeine, and the branched chain amino acids (BCAA). A proven ergogenic efficacy was found in: a) sodium bicarbonate in high-intensity exercise, b) creatine in exercise performance for sport events that require explosive, high-energy output activities, and c) caffeine in both prolonged endurance exercise and short-term intense exercise lasting approximately five minutes.

Conclusions: The supplements have potential adverse effects so their use must be always prescribed by a sports physician in accordance with the needs and the medical history of the athlete. Moreover, further research is needed (including large scale follow-up studies) so as to draw definite conclusions about their long-term health safety.

Keywords: Suppplements; Energy; Exercise; Sports Performance

Abbreviations: HMB: beta-Hydroxy-beta-Methyl-Butyric acid; BCAA: Branched Chain Amino Acids; MSUD: Maple Syrup Urine Disease

\section{Introduction}

The "ergogenic" nutritional supplements are substances that supposedly improve the body's work capacity and athletic performance. Dozens of "ergogenic" preparations are marketed today accompanied by nutrition and health claims. These products are commercially successful and consumed by athletes and exercisers. However, athletes who use supplements usually consume quantities much higher than those indicated, while a high supplement dosage does not necessarily leads to an increase of the athlete's performance. Overdose of supplements may cause multiple adverse effects in the body. The available literature is still lacking conclusive information, while there is a large heterogeneity in the reported scientific data. Moreover, evidence-based recommendations for ergogenic supplementation are lacking.

\section{Objective}

The aim of the present study is to investigate the role of legally available (according to the World Anti-Doping Code) [1] ergogenic nutritional supplements in exercise performance using a biochemical and physiological approach.

\section{Material}

The literature available in the online databases Medline, PubChem, Toxnet, and Google Scholar was used. 


\section{Method}

The research methodology refers to the brief review of the available published scientific studies. The literature search was conducted using the following terms / keywords: "ergogenic supplements", "ergogenic aids" and "exercise performance".

\section{Results}

According to the search results the most popular and commonly used legally available "ergogenic" supplements by athletes are sodium bicarbonate, beta-alanine, beta-hydroxybeta-methylbutyric acid (HMB), creatine, carnitine, caffeine, and the branched chain amino acids (BCAA).

\section{Sodium bicarbonate}

Sodium bicarbonate is the chemical compound with the formula $\mathrm{NaHCO}_{3}$. By buffering acidity in the blood, bicarbonate may be able to draw more of the acid produced within the muscle cells out into the blood and thus reduce the level of acidity within the muscle cells themselves [2]. $\mathrm{NaHCO}_{3}$ may affect muscle physiology and motor pathways associated with early rate of force development and/or the metabolic properties associated with contractile shortening velocity, and this effect appears more pronounced in fast-twitch fibres [3]. Current research would suggest that as an ergogenic aid $\mathrm{NaHCO}_{3}$ can improve high-intensity exercise, within a range of exercise modalities, such as a single bout of supramaximal exercise, high-intensity intermittent activity, and skill-based sports [4].

The most common dosage is $0.3 \mathrm{~g} \mathrm{NaHCO}_{3}$ per $\mathrm{kg}$ of body weight, taken 1-3 hours before exercise. This is a relatively large quantity, and could cause side effects [5]. There have been potential acute adverse effects of severe alkalosis associated with the use of increased doses of bicarbonate. Additionally side effects like vomiting, gastrointestinal discomfort, bloating, and diarrhea may occur particularly if sufficient water is not taken with sodium bicarbonate. Currently, there are no data regarding the long term adverse consequences of $\mathrm{NaHCO}_{3}$ [2].

\section{Beta-alanine}

Beta-alanine (3-aminopropanoic acid) is formed in vivo by the degradation of dihydrouracil and carnosine. It is a component of the naturally occurring peptides carnosine and anserine and also of pantothenic acid (Vitamin B-5) which itself is a component of coenzyme A. Under normal conditions, betaalanine is metabolized into acetic acid [6]. The theoretical basis/ claim is that it may increase physical performance during shortduration, high-intensity exercise. However, a cause and effect relationship has not been established between the consumption of beta-alanine and an increase in physical performance during short-duration, high intensity exercise [7] Moreover, the accumulation of $\beta$-alanine occurs in $\beta$-alaninemia, an inborn error of metabolism.

Patients with $\beta$-alaninemia may develop neurological abnormalities. Oxidative stress and alteration of the phosphoryltransfer network may be involved in the pathophysiology of $\beta$-alaninemia. The ingestion of $\beta$-alanine to improve muscular performance deserves more attention in respect to possible side-effects [8]. A common sensory adverse side effect of $\beta$-alanine is skin paresthesias including itch and tingling [9]. There is insufficient evidence examining the safety of beta-alanine supplementation and its side effects. It is therefore recommended to err on the side of caution in using beta-alanine as an ergogenic aid until there is sufficient evidence confirming its safety [10].

\section{Beta-hydroxy-beta-methylbutyric acid (HMB)}

HMB is a metabolite of the amino acid leucine [11]. The theoretical basis/claim is that HMB reduces muscle tissue damage during exercise, increase in lean body mass, increase muscle strength, increase endurance performance, skeletal muscle tissue repair, and faster recovery from muscle fatigue after exercise [12]. However, a number of studies conflict with research that supports the use of HMB supplementation and do not support its efficacy. More studies are needed to determine the overall efficacy and safety of HMB supplementation as an ergogenic aid for athletes $[5,11,13,14]$.

\section{Creatine}

The relative importance of creatine during exercise is dependent on the nature of the exercise. It is considered to induce a small improvement in exercise performance in sport events that require explosive, high-energy output activities especially of a repeated nature, but it did not appear to enhance aerobic activities [14]. The recommended dosage is five days of creatine loading (10- $20 \mathrm{~g}$ per day in 2-4 equal portions), followed by a maintenance dose of 2-3 g per day [14]. However, there is a lack of robust data regarding the safety of long-term creatine supplementation, particular at doses higher than recommended [14]. Health risks of excess creatine supplementation include liver dysfunction, and kidney impairment. Regular monitoring is compulsory to avoid any abnormal reactions during oral creatine supplementation [15].

\section{Carnitine}

L-carnitine is a conditionally essential amino acid-like compound involved in the transport of long-chain fatty acids into the mitochondria during the beta-oxidation process $[16,17]$. The theoretical basis/claim is that it helps the body to burn fat. Unfortunately, carnitine supplementation does not increase the muscle content of it. Moreover, well-designed scientific studies show that carnitine does not increase aerobic ability and endurance or decrease body fat [5]. Studies provided no basis for the use of carnitine intended as nutritional ergogenic aid to meet the expenditure of intense muscular effort and especially for sportsmen [13,14]. Adverse effects of carnitine include nausea, vomiting, abdominal cramps, diarrhea, and a "fishy" body odor. More rare side effects include muscle weakness in uremic patients and seizures in those with seizure disorders [18]. 


\section{Caffeine}

Caffeine is the most widely consumed central-nervoussystem stimulant. A mechanism of action is the antagonism at the level of adenosine receptors. It activates noradrenaline neurons and seems to affect the local release of dopamine [19]. The theoretical basis of its ergogenic potential is related with its psycho stimulant effects, the activation of lipolysis in adipose tissue, and the increase of muscle contractility [5]. Caffeine ingestion prior to exercise enhances performance of both prolonged endurance exercise and short-term intense exercise lasting approximately five minutes. The ergogenic effects of caffeine were observed at doses of about $3 \mathrm{mg} / \mathrm{kg}$ bw consumed prior to exercise [14]. However, this dosage corresponds to at least three cups of strong instant coffee for an average person. Such amount may lead to adverse effects, so it should not be tested for the first time before an important match [5]. Potential adverse effects of caffeine on human health include general toxicity, cardiovascular effects, effects on calcium balance and bone status, behavioural effects in adults and children, carcinogenic potential, genotoxic potential, and reproductive effects, including pre -and postnatal development [20].

\section{Branched chain amino acids (BCAA)}

The BCAA leucine, isoleucine, and valine participate in a variety of important biochemical functions in the brain [21]. Moreover, it is claimed that BCAA could play a role as ergogenic aids. However, the effects of BCCA supplementation on exercise performance are mixed, and the published studies often suffer from methodological flaws [22]. Studies provided no basis for the use of BCAA intended as nutritional ergogenic aids to meet the expenditure of intense muscular effort and especially for sportsmen [14]. It should be mentioned that in individuals with maple syrup urine disease (MSUD) the plasma concentrations of the BCAA are extremely high naturally. The functional consequences of MSUD, therefore, could potentially provide insight into central nervous system aberrations that might be expected when excessive amounts of the BCAAs are ingested [21].

\section{Discussion}

The vast majority of supposed ergogenic nutritional supplements has not proven yet an ergogenic effect (except sodium bicarbonate, creatine, and caffeine) [5,14]. To demonstrate the ergogenic effect of a substance scientific studies require a satisfactory number of subjects, and should be designed to exclude the effect of other factors on measurable performance indicators. In many countries the manufacture of nutritional supplements is not appropriately regulated by the state. In practical terms this means that the ingredients may not correspond to those indicated on the label and in some cases the non-listed substances in the supplement may include a substance that is prohibited under the regulations against doping. Even in cases where the supplements industry is covered by strict rules and regulations, adulteration of supplements is possible (either accidentally or intentionally). There is no $100 \%$ guarantee for the athlete that a supplement contains no forbidden substance [13].

Moreover, most supplements manufacturers have claims for products that are not supported by sound scientific research and rarely inform the consumer about potential adverse effects. Athletes should take appropriate help to distinguish marketing strategies from reality. The "ergogenic" dietary supplements are available easily and any can be ordered from the internet without supervision or penalties to suppliers. Scientific community (sports scientists, biochemists, and medical professionals) should focus in collecting information for the acute and chronic health effects from the use or misuse of ergogenic aids by athletes, in order to inform stakeholders and to disseminate scientific knowledge to the general public. It is worth highlighting that : a) the term "natural" does not mean "safe", b) the use of the necessary "ergogenic" preparations should be done only when is needed and is prescribed by qualified medical personnel, c) when it is necessary to obtain "ergogenic" products well known pharmaceutical companies should be preferred, d) supplements are taken at an athlete's risk and personal responsibility, and in accordance with the World Anti-Doping Code «ignorance is no excuse» $[1,23]$.

\section{Conclusion}

The findings of this brief review suggest that only a few legally available nutritional supplements have a proven ergogenic efficacy: a) NaHCO3 in high-intensity exercise, within a range of exercise modalities, b) creatine in exercise performance for sport events that require explosive, high-energy output activities, and c) caffeine in both prolonged endurance exercise and short-term intense exercise lasting approximately five minutes. However, the supplements have potential adverse effects so their use must be always prescribed by a sports physician in accordance with the needs and the medical history of the athlete. Moreover, further research is needed (including large scale follow-up studies) so as to draw definite conclusions about their long-term health safety.

\section{Conflict of Interests}

The author declares that there is no conflict of interests regarding the publication of this paper.

\section{Funding statement}

This study received no grant from any funding agency in the public, commercial or not for-profit sectors.

\section{Disclaimer}

Dr. Delimaris contributed to this article in his personal capacity. The views expressed are his own and do not necessarily represent the views of the Greek Ministry of Education, Research and Religious Affairs. The appearance of supplements references in the publication is not an approval of the supplements or of their effectiveness, quality or safety. 


\section{References}

1. World Anti-Doping Code (2016) Therapeutic Use Exemptions. International Standart Prohibited List.

2. Shelton Jose, Gideon V Praveen Kumar (2010) Sodium Bicarbonate-A Potent Ergogenic Aid?. Food and Nutrition Sciences 1(1): 1.

3. Siegler JC, Marshall PW, Bishop D, Shaw G, Green S (2016) Mechanistic Insights into the Efficacy of Sodium Bicarbonate Supplementation to Improve Athletic Performance. Sports Med Open 2(1): 41.

4. McNaughton LR, Gough L, Deb S, Bentley D, Sparks SA (2016) Recent Developments in the Use of Sodium Bicarbonate as an Ergogenic Aid. Curr Sports Med Rep 15(4): 233-244.

5. Mougios V (2005) New data about nutritional supplements: promises and pitfalls, Seminar of applied sports nutrition (in Greek), Department of Physical Education and Sports Science, Aristotle University of Thessaloniki, Greece.

6. Beta-Alanine, Human Metabolome Database.

7. Carlo Agostoni, Roberto Berni Canani, Susan Fairweather-Tait, Marina Heinonen, Hannu Korhonen (2014) Scientific Opinion on the substantiation of a health claim related to beta-alanine and increase in physical performance during short-duration, high-intensity exercise pursuant to Article 13(5) of Regulation (EC) No 1924/2006. EFSA Journal 12(7): 3755, 11 pp.

8. Gemelli T, de Andrade RB, Rojas DB, Bonorino NF, Mazzola PN, et al. (2013) Effects of $\beta$-alanine administration on selected parameters of oxidative stress and phosphoryltransfer network in cerebral cortex and cerebellum of rats. Mol Cell Biochem 380(1-2): 161-170.

9. Liu Q Sikand P, Ma C, Zongxiang Tang, Liang Han, et al. (2012) Mechanisms of itch evoked by $\beta$-alanine. J Neurosci 32(42): 1453214537.

10. Quesnele JJ, Laframboise MA, Wong JJ, Kim P, Wells GD (2014) The effects of beta-alanine supplementation on performance: a systematic review of the literature. Int J Sport Nutr Exerc Metab 24(1): 14-27.

11. Wilson GJ, Wilson JM, Manninen AH (2008) Effects of beta-hydroxybeta-methylbutyrate (HMB) on exercise performance and body composition across varying levels of age, sex, and training experience: A review. Nutr Metab (Lond) 5: 1
12. EFSA Panel on Dietetic Products, Nutrition and Allergies (NDA) (2011) Scientific Opinion on the substantiation of health claims related to $\beta$-hydroxy $\beta$-methylbutyrate monohydrate (HMB) alone or in combination with $\alpha$-ketoisocaproic acid (KIC) and reduction of muscle tissue damage during exercise (ID 1577, 1584), increase in lean body mass (ID 1579, 1582, 1583), increase in muscle strength (ID 1578, $1583,1587)$, increase in endurance performance (ID 1580, 1581), skeletal muscle tissue repair (ID 1586) and faster recovery from muscle fatigue after exercise (ID 1576, 1585) pursuant to Article 13(1) of Regulation (EC) No 1924/2006. EFSA Journal 9(6): 2227 [23 pp].

13. Schizas K (2006) Nutritional aids (in Greek), Cyprus Society of Sports Medicine.

14. EFSA (European Food Safety Authority) (2015) Scientific and technical assistance on food intended for sportspeople. EFSA Journal 12(9): EN871, $32 \mathrm{pp}$.

15. Poortmans JR, Francaux M (2000) Adverse effects of creatine supplementation: fact or fiction? Sports Med 30(3): 155-1570.

16. Villani RG, Gannon J, Self M, Rich PA (2000) L-Carnitine supplementation combined with aerobic training does not promote weight loss in moderately obese women. Int J Sport Nutr Exerc Metab 10(2): 199207.

17. Hathcock JN, Shao A (2006) Risk assessment for carnitine. Regul Toxicol Pharmacol 46(1): 23-28.

18. NIH/ODS (2006) Dietary Supplement Fact Sheets on Carnitine.

19. Nehlig A, Daval JL, Debry G (1992) Caffeine and the central nervous system: mechanisms of action, biochemical, metabolic and psychostimulant effects. Brain Res Brain Res Rev 17(2): 139-170.

20. Nawrot P, Jordan S, Eastwood J, Rotstein J, Hugenholtz A, et al. (2003) Effects of caffeine on human health. Food Addit Contam 20(1): 1-30.

21. Fernstrom JD (2005) Branched-chain amino acids and brain function. J Nutr 135(6 Suppl): 1539S-46S.

22. Davis JM (1995) Carbohydrates, Branched-Chain Amino Acids, and Endurances: The Central Fatigue Hypothesis. Int J Sport Nutr 5(s1): S29-S38.

23. Koutlianos N (2015) Ergogenic substances and athletic performance, 3rd Congress of Sport Science, Department of Physical Education and Sport Science, University of Athens, Greece, pp. 20.
Your next submission with Juniper Publishers will reach you the below assets

- Quality Editorial service

- Swift Peer Review

- Reprints availability

- E-prints Service

- Manuscript Podcast for convenient understanding

- Global attainment for your research

- Manuscript accessibility in different formats (Pdf, E-pub, Full Text, Audio)

- Unceasing customer service

Track the below URL for one-step submission https://juniperpublishers.com/online-submission.php 